\title{
Representações da pele na experiência do sexo bareback entre homens na cidade do Rio de Janeiro
}

Vladimir Bezerra ${ }^{1}$

Fundação Oswaldo Cruz

Resumo: Este artigo, fragmento de uma pesquisa etnográfica realizada entre os anos de 2017 e 2018 na cidade do Rio de Janeiro que investigou grupos específicos de homens que se relacionam sexualmente com outros homens sem o uso do preservativo, tem por objetivo refletir sobre sentidos e valores conferidos por estes homens à pele, categoria que tem posição nuclear dentro da experiência do que chamam de "sexo sem capa". Afinal, no contexto dos riscos que envolvem a prática do sexo "sem capa", quais as representações da pele que emergem dos sujeitos que se lançam à experiência bareback?

Palavras-chave: sexo bareback; sexualidade; corpo; etnografia; psicologia. 


\title{
Representations of the skin in the bareback sex experience between men in Rio de Janeiro
}

\begin{abstract}
This article, a fragment of an ethnographic research carried out between the years 2017 and 2018 in the city of Rio de Janeiro that investigated specific groups of men who engage sex with other men without the use of condoms, has the intention to reflect on the meanings and values conferred by these men to the skin, a category that have a nuclear position within the experience of what they call bareback sex. After all, in the context of the risks involved in barebacking, what are the representations of the skin in the bareback experience according to these men?
\end{abstract}

Keywords: bareback sex; sexuality; body; ethnography; psychology.

\section{Representaciones de la piel en la experiencia del sexo bareback entre hombres en la ciudad de Rio de Janeiro}

\begin{abstract}
Resumen: Este artículo, un fragmento de una investigación etnográfica realizada entre 2017 y 2018 en la ciudad de Rio de Janeiro que investigó grupos específicos de hombres que se relacionan sexualmente con otros hombres sin el uso de condones, tiene como objetivo reflexionar sobre los significados y valores conferidos por estos hombres a la piel, categoría que tiene posición nuclear dentro de la experiencia de lo que llaman "sexo a pelo" u sexo bareback. En el contexto de los riesgos que implican la práctica del sexo "bare", ¿̇cuáles son las representaciones de la piel que surgen de los sujetos que se lanzan a la experiencia "a pelo"?
\end{abstract}

Palabras clave: sexo a pelo; sexualidade; cuerpo; etnografia; psicologia 
$\mathrm{E}$ ste artigo, oriundo de uma pesquisa realizada ${ }^{2}$ entre os anos de 2017 e 2018, na cidade do Rio de Janeiro, em meio a grupos específicos de homens que se relacionam sexualmente com outros homens, praticantes exclusivamente do sexo sem preservativo, tem por objetivo problematizar e refletir sobre alguns sentidos e valores que os praticantes de bareback conferem à pele no contexto da experiência do que chamam de sexo "sem capa".

O conjunto de dados que proporcionam as reflexões aqui contidas é oriundo de um trabalho mais amplo de pesquisa desenvolvido a partir de uma metodologia qualitativa. Para se pensar o sexo "sem capa" empreendeu-se: a) uma revisão bibliográfica de pesquisas sobre sexualidade e sexo bareback ${ }^{3}$ numa perspectiva interseccionalizada; b) análises de boletins epidemiológicos e comportamentais do Ministério da Saúde e organizações não governamentais (ONGs); c) uma incursão ao ambiente virtual (acompanhamento de fóruns de discussão e de comunidades de praticantes do sexo sem preservativo); e d) um trabalho etnográfico que privilegiou a observação participante em interações sexuais e/ou em conversas informais em diferentes contextos de homossocialização.

O trabalho inicial de revisão bibliográfica e análise de boletins de saúde revelou um dado inicial inquietante: a prática de sexo sem preservativo não é uma exclusividade de homens que se relacionam sexualmente com outros homens. Pesquisadores da área da saúde coletiva (MAKSUD et al., 2015; SILVA, 2009) consideram que o pleno reconhecimento do preservativo como método preventivo entre a população brasileira como um todo (BRASIL, 2011: 26) 4 não incide sobre seu uso nas relações sexuais. Uma visita aos dados dos boletins epidemiológicos do Ministério da Saúde (2017a) 5 sobre o vírus da imunodeficiência (HIV) e infecções sexualmente transmissíveis (ISTs) (BRASIL, 2017b) aponta para um aumento das taxas de novas infecções por HIV e sífilis adquiridas por contato sexual direto no país ${ }^{6}$. Especificamente sobre a sífilis adquirida por contato sexual, observou-se em 2016 um aumento de 26,8\% em comparação com o ano de 2015. Entretanto, o boletim sobre sífilis informa que os homens das regiões sudeste e sul do país, na faixa etária entre 20 e 29 anos, estão entre os mais vulneráveis (BRASIL, 2017b: 11).

\footnotetext{
${ }^{2}$ Dissertação de mestrado intitulada $O$ sexo 'na pele': sentidos do corpo e da pele na experiência do sexo bareback entre homens na cidade do Rio de Janeiro, defendida em março de 2019, no Programa de Pós-Graduação em Ciências Sociais da Pontifícia Universidade Católica do Rio de Janeiro, sob orientação de Sônia Giacomini e coorientada por Roberto DaMatta.

3 Estudos no campo da Antropologia e Psicologia.

4 Dados oriundos da Pesquisa sobre Comportamento, Atitudes e Práticas na População Brasileira (PCAP).

5 Dados ainda mais recentes estão disponíveis em: http://www.aids.gov.br/system/tdf/pub/2016/67064/boletim ist aids 2019 especial versao web.pdf?file $=1 \&$ type $=$ node\&id $=67064 \&$ force $=1$. Acesso em 02 dez. 2019.

${ }^{6}$ Considerando os últimos 4 boletins epidemiológicos do Ministério da Saúde. Para informações sobre a sífilis no Brasil, acessar http://www.aids.gov.br/pt-br/pub/2017/boletim-epidemiologico-de-sifilis-2017. Acesso em 4 mar 2018. Para outras informações sobre o vírus HIV no mundo, acessar o relatório do programa internacional Joint United Nations Program on HIV/AIDS (UNAIDS), disponível em https://www.unaids.org/en/resources/documents/2017/2017 data book. Acessos em 4 dez. 2019.
} 
Antes de prosseguir, cabe salientar que, sobretudo no campo das ciências humanas e sociais, o termo "vulnerabilidade" tem sido colocado sob escrutínio uma vez que muitas vezes a expressão é empregada sem que sejam considerados os condicionantes sociais que incidem sobre ela. Dessa forma, este artigo alinha-se à proposta de Anahi Guedes de Mello (2016: 3274), que indica que a vulnerabilidade "deve ser compreendida como um indicador da desigualdade social que se expressa nos processos de exclusão de grupos sociais que têm sua capacidade de ação e reação reduzida em função da discriminação e opressão a que são submetidos".

Partindo desse entendimento, o conjunto de dados epidemiológicos informa que não apenas existem diversos modos de transmissão de determinadas infecções sexualmente transmissíveis, mas também registra um fato inconteste: o sexo sem preservativo configura-se uma realidade7 entre a população brasileira (MAKSUD et al., 2015; SILVA, 2009).

Elegeu-se como ponto focal para estas notas uma das descobertas etnográficas da pesquisa: a preponderância do sentido tátil como produtor de subjetividades. Como pontuo em outro artigo ${ }^{8}$ (BEZERRA e GIACOMINI, 2019), na dimensão das experiências observadas, o corpo que ultrapassa a dimensão biológica, se inscreve no registro da "ordem simbólica" (MIJOLLA, 2005: 1732) e forma um alicerce que comporta a totalidade do campo de ação e de existência do homem (LACAN, 1966/1998).

Circunscrita nessa noção de corpo, a pele assume um locus central nas narrativas. Com isso, as costuras analíticas realizadas neste trabalho privilegiam um afastamento e questionamento do eixo normal - patológico (CANGUILHEM, 2009), privilegiando reflexões sobre a pele a partir de seus próprios elementos e daquilo que reverbera dela e para ela, antes, durante e após os encontros sexuais observados.

Os dados do próprio campo de pesquisa oferecem elementos capazes de evidenciar que a prática do sexo "sem capa" representa para seus praticantes muito menos um distúrbio (psicológico ou social) e mais um fenômeno social forjado no decorrer das últimas três décadas (BEZERRA, 2019), capaz de produzir subjetividades e instituir novas normas sobre os corpos na contemporaneidade. É desta outra perspectiva que se pretende pensar as representações sobre a pele na experiência do sexo bareback neste artigo.

A pesquisa realizada durante o mestrado desenvolveu-se a partir de um referencial teórico das ciências sociais, com especial influência de autores como Anthony Giddens e David Le Breton. Contudo, dada a relevância e a presença do assunto no campo da saúde, destacam-se autores que, como Ivia Maksud, Inês Dourado, Maria Elvira Díaz-Benítez, Richard Parker, Maria Luíza Heilborn, Jane Russo, Sergio Carrara, no interior do campo da Saúde Coletiva, privilegiam uma perspectiva analítica interdisciplinar e que congregam as ciências sociais e humanas.

Conforme indica Birman (1991), a multidisciplinaridade é a marca do campo da saúde coletiva, já que sua problemática demanda leituras distintas e permite a construção de diferentes objetos teóricos. Desta maneira, apoia-se na concepção aberta e multidisciplinar da antropologia, "ciência da diferença" (ROCHA, FRID,

\footnotetext{
7 Em entrevista à Associação Brasileira de Saúde Coletiva (Abrasco), o professor Richard Parker afirma: "É preciso assumir o fracasso da prevenção no Brasil”. Ver mais em: http://agenciaaids.com.br/noticia/e-preciso-assumir-o-fracasso-daprevencao-no-brasil-afirma-richard-parker/. Acesso em 13 ago. 2018.

${ }^{8}$ Sobre o amplo espectro de representações do corpo na experiência do sexo sem preservativo entre homens ver mais em "O sexo 'sem capa': notas etnográficas sobre o corpo na experiência bareback entre homens" (BEZERRA e GIACOMINI, 2019).
} 
2015: 14), que promove o exercício permanente de abordagens etnográficas, históricas e comparativas, além de amparar o trabalho clínico em psicologia. Partindo dessa ótica, empreendem-se pequenos diálogos entre a antropologia, a sociologia e a teoria psicanalítica, o que evidencia não apenas a multidisciplinaridade, mas a interdisciplinaridade do estudo, já que se trata de pensar a sexualidade, um tema que se não se encerra em um campo de conhecimento específico, tampouco está fechado em si mesmo.

Este artigo está dividido em duas partes; a primeira explicita suscintamente as principais motivações pessoais, as influências e a abordagem metodológica para o desenvolvimento da pesquisa num amplo espectro. A segunda parte busca empreender uma discussão multi/interdisciplinar - a partir das narrativas, diferentes cenários e dinâmicas observadas -, com foco sobre os sentidos e valores que os praticantes do sexo "sem capa" depositam sobre a pele.

\section{Prática clínica, ressonâncias dos estudos de gênero e metodologia}

A inclinação em realizar uma pesquisa sobre o sexo bareback está ligada a uma prática clínica em psicologia guiada em grande parte pela teoria psicanalítica, voltada para questões de orientação sexual, identidade de gênero e sexualidade entre adolescentes e jovens adultos nos âmbitos privado e público 9 . O cotidiano de atendimentos evidencia uma variedade de casos circunscritos na dimensão do comportamento sexual, mais especificamente casos em que a infecção pelo vírus da imunodeficiência (HIV) se torna o core do processo psicoterapêutico de alguns indivíduos: "curto direto na pele, é mais gostoso!", diz o jovem de 23 anos, em processo de análise há seis meses. Desta maneira, este contexto estimula profissionais da saúde mental inseridos em serviços públicos ou privados a refletir criticamente sobre suas práticas, em busca de um fazer clínico que não apenas acompanhe as diversas transformações sociais no decorrer dos séculos, mas que apresente um discurso crítico sistemático sobre a cultura (BIRMAN, 1999, 2009).

No que se refere ao diálogo multi/interdisciplinar desta pesquisa, são os estudos de Sandra Azerêdo (1998, 2010) que influenciaram positivamente o viés da pesquisa. Em "Encrenca de gênero nas teorizações em Psicologia”, ao citar James Clifford ("para teorizar, é preciso sair de casa"), a autora indica que teorizar sobre gênero é a possibilidade de "considerar os processos de subjetivação que nos constituem e também levar em conta o político (...), este tem sido um ponto cego nas teorizações em Psicologia" (AZERÊDO, 2010: 184-185). De um modo geral, para Azerêdo, o encontro da psicologia com os estudos de gênero, que tem como referência os estudos de Gayle Rubin e Judith Butler, tem produzido efeitos vantajosos e desafiantes ao se introduzir teorias que privilegiam a intensificação do diálogo interdisciplinar, na construção do conhecimento no campo do gênero e das sexualidades. Nesse sentido, os estudos de gênero têm auxiliado profissionais a repensar uma escuta clínica que se depara com fenômenos sociais contemporâneos, que expõem um "eu" que se localiza em posição privilegiada (BIRMAN, 1999; LASCH, 1983; DEBORD, 1997; FORTES et al., 2018) na contemporaneidade.

9 Publicações anteriores sobre o tema incluem os artigos "Práticas e sentidos da sexualidade de alguns usuários da profilaxia pré-exposição (PrEP) ao HIV" (BEZERRA, 2017) e "Bareback, Risco e Prazer na Perspectiva de Usuários da Profilaxia Pré-exposição (PrEP) ao HIV: um estudo netnográfico" (BEZERRA e SILVA, 2019). 


\section{A abordagem metodológica: uma "pequena" nota importante sobre a etnografia}

De modo geral, a maior parte das pesquisas sobre sexualidade no Brasil se baseia metodologicamente em questionários ou entrevistas formais, características, por exemplo, de pesquisas na área da saúde (BRAZ, 2012; DÍAZ-BENÍTEZ, 2007). Diferentemente das pesquisas antropológicas, pesquisas no campo da saúde são reguladas pela resolução número 196/1996 do Conselho Nacional de Saúde (CNS), que instituiu uma série de orientações e normas para controlar pesquisas envolvendo seres humanos. Desde outubro do ano de 1996, pesquisas que envolvem seres humanos passam obrigatoriamente pelo crivo de comitês de ética em pesquisa às quais estes trabalhos estão vinculados antes de serem desenvolvidas efetivamente. Por outro lado, como pontua Cristina Dias da Silva (2005: 187),

grande parte dos termos da Resolução 196/96 versa sobre casos explicitamente referidos a pesquisas típicas da área biomédica. Considerando que os seres humanos estão presentes, mesmo que de outra forma, nos estudos de muitos pesquisadores da área de humanidades, com especial destaque para antropólogos, cujo trabalho de campo possibilita um contato face a face e constrói uma relação de interlocução com os pesquisados, é de se admirar que não haja nenhuma menção sobre qualquer especificidade ou ressalva para o tipo de trabalho realizado por esses profissionais.

Dado este rápido panorama, as reflexões aqui contidas priorizam o que Roberto DaMatta $(1978,2010)$ e Silva (2009) indicam ser a necessidade de um travelling a outros universos sociais, de modo a "possibilitar o encontro do eu com o outro, percebendo como são conectadas essas figuras do encontro" (AZERÊDO, 2010: 184).

Como bem pontuam DaMatta (2010, 1978), Geertz (2004) e Malinowski (1978), o enfoque etnográfico de pesquisa busca menos uma explicação e mais uma compreensão de inúmeras dinâmicas na formação das sociedades, além de captar seus códigos, normas, valores e modos de organização (BEZERRA, 2019). Logo, além da revisão bibliográfica e documental e da pesquisa em plataformas virtuais, priorizou-se o mergulho em um trabalho tipicamente etnográfico, que envolveu um trabalho de campo com observação direta, "acompanhante” (DÍAZBENÍTEZ, 2007) de interações sexuais e de reuniões informais entre/e com homens praticantes de sexo bareback, em cenários relacionados (ou não) com a prática de sexo, onde os limites físicos e simbólicos entre o pesquisador e o campo eram constantemente deslocados.

Por fim, antes de avançar na discussão e como particularidade marcante do trabalho, vale ressaltar que, assim como nas pesquisas de Díaz-Benítez (2007) e Braz (2012), o trabalho de campo desta pesquisa revelou situações em que os próprios pesquisadores podem ser não apenas observadores, mas também objetos de negociações e situações onde seus lugares no campo são questionados e os limites entre pesquisador e campo estudado são constantemente deslocados.

Partindo deste rápido panorama, pergunta-se: o que representa a pele na experiência do sexo "sem capa"? Quais os sentidos e valores que praticantes masculinos exclusivamente do sexo bareback depositam sobre suas peles? 


\title{
Observando a "foda sem capa": uma perspectiva e uma discussão sobre a pele
}

\author{
Corpo da "foda": pequena nota
}

Inicialmente evidencia-se nas narrativas a hegemonia de um corpo específico, que transborda a noção de biológico e se mostra um locus de intensidade, ampliando alguns entendimentos sobre a problemática da corporeidade na contemporaneidade (BEZERRA e GIACOMINI, 2019).

Tal compreensão remete ao movimento de Freud $(1905,1914)$ que, ao progressivamente afastar-se da racionalidade médico-psiquiátrica do final do século XIX, inaugura um espaço científico onde o corpo do sujeito pode ser pensado como, conforme pontuam Isabel Fortes, Monah Winograd e Simone Perelson (2018), o lugar de "dupla racionalidade" (FORTES et al., 2018: 282): o corpo representacional e corpo do transbordamento, desvelando-se um corpo erógeno ou pulsional.

Deixando de lado a ideia de uma pedagogia racional, unitária, homogênea e totalizante, Freud no decorrer de sua obra propõe pensar o corpo dentro das noções de temporalidade e espacialidade. Segundo aponta Sherrine Njaine Borges (1996), a partir de 1914, Freud indica um eu que se desdobra em uma imagem que não pode coincidir com o eu da inibição, do controle. Este "eu" desdobrado "destrona a razão, e sua pedagogia pretendente a protagonista (...), é libidinizado e, portanto, sujeito a incertezas, erros, desvarios, paixões absurdas" (BORGES, 1996: 36). Eis aí, portanto, um eixo do pensamento freudiano que fornece uma pista para pensar o corpo do sexo bareback, indicando um corpo que "não tem lugar fixo, seu destino é incerto, não pode ser previsto de antemão" e que, "no lugar da linearidade temporal, o processo educativo passa a ser pensado em ciclos, retornos, combinações, simultaneidades, e sobredeterminações" (BORGES, 1996: 36-37).

Saliento que a noção de dupla racionalidade parece se aplicar a estas reflexões à medida em que os corpos observados parecem se constituir "na interseção entre o psíquico e o somático, ou seja, no jogo complexo e multidimensional entre o material (o orgânico), o imaterial (o representacional) e uma espécie de mistura indiscernível entre os dois (o pulsional)" (FORTES et al., 2018: 279). Nessa perspectiva, as narrativas indicam que é possível compreender que os corpos na "foda" bareback operam como elementos fundamentais na produção de "verdades" que se transformam de acordo com o tempo e o espaço que estes corpos transitam (BEZERRA, 2019; BEZERRA e GIACOMINI, 2019).

Mais do que entendimentos herméticos, ou resolvidos, a análise de muitas narrativas sobre o sexo bareback levou a pesquisa a se deparar com um corpo consonante com os contextos de homossocialização visitados. Estes são lugares impermanentes, imprevisíveis, permeados pelo que os praticantes denominam "desejo" e inscritos no que Mary Jane Spink (2001) define como positivação da experiência do "risco" (SPINK, 2001; CASTIEL, GUILAM e FERREIRA, 2010, LE BRETON, 2000, 2007, 2011, 2013, 2016), um risco "escolhido" (DOUGLAS e WILDAVSKY, 2012), aspectos que uma vez trazidos à tona desvelaram a pele como um elemento central no imaginário dos homens considerados para esta pesquisa. 


\title{
O sexo "na pele": uma experiência paradoxal
}

De um modo geral, a pele é um tema debatido por alguns pesquisadores da psicanálise, como Christian Dunker e Tatiana Assadi em uma série de artigos organizados na obra A pele como litoral: fenômeno psicossomático e psicanálise (RAMIREZ et al., 2011). A filosofia também se ocupa de reflexões - como nos escritos da pesquisadora Maria Cristina Franco Ferraz (2014: 62) que, em seu artigo "Estatuto paradoxal da pele e cultura contemporânea: da porosidade à pele-teflon", aponta que

\begin{abstract}
a pele que acreditamos fechar e "conter" nossos corpos é dotada de um estatuto paradoxal que se torna cada vez mais oportuno tematizar, no contexto da expansão e consolidação da cultura da imagem, do espetáculo, a performance bem-sucedida e dos modos de vida com ela compatíveis. De início, lembremos que a pele é meio de comunicação por excelência, verdadeira interface dentro/fora, membrana de trânsito e trocas com o que costumamos chamar de "meio ambiente". Não se trata, portanto, de um mero "invólucro" ou "embalagem".
\end{abstract}

Na antropologia, David Le Breton (2016, 2003) é um dos representantes do debate sobre o estatuto da pele através de pesquisas que a compreendem como um meio por onde os sujeitos estabelecem pontes entre suas subjetividades e o mundo exterior. Nas palavras de Le Breton (2016: 20), "matriz dos outros sentidos, a pele é uma vasta geografia nutritiva das sensorialidades diferentes, ela as engloba sob seu guarda-chuva, abrindo ao homem dimensões singulares do real que não saberíamos isolá-las umas das outras".

\begin{abstract}
Extratos do diário de campo
Já eram 19h quando cheguei na casa de M., no bairro do Rio Comprido. Ao abrir a porta, M., completamente nu e com um aparelho de barbear na mão, me convida a entrar em tom apressado, soltando a frase "Anda, vem!", correndo em direção ao banheiro. Eu o acompanhei sem entender exatamente o que acontecia. Já no banheiro, M. apressadamente passava mais espuma de barbear no peito - "Já raspei as pernas, falta aqui [apontando para o peito] e meu cu", me disse sorrindo. Eu ali, sentado em um banquinho no corredor, observava como cuidadosamente M. raspava cada pelo de seu corpo. "Lisinho, bem lisinho, pra sentir tudinho" (olhando pra mim, pro espelho e sorrindo), dizia M. que "(...) não tem sensação melhor, quando naquela pegação, naquela putaria, a gente sente a pele bater na pele, quando o cara esfrega o pau no meu peito, na minha cara, quando eu lambo, é diferente quando é direto, sem borracha, na pele é pra valer".

Certa vez, disse B.: "Ontem comi um cara pra valer, a gente começou com a borracha no meio da pista de dança, ele chupava meu pau já na camisinha, um saco, beijava a boca dele e aquele gosto escroto de lubrificante, de coisa artificial, (...) lá pelas tantas eu arranquei aquela merda do pau, ele me olhou e só pela olhada eu entendi que ele queria, não tem jeito, na pele é mais real, é mais orgânico (...) menos artificial, é contato direto, se misturar com os caras de verdade".
\end{abstract}

Se as contribuições de Le Breton são o ponto de partida deste subcapítulo, é importante sinalizar que alguns outros pesquisadores - como Lionel Tiger (2003) e Luiz Fernando Dias Duarte (1999) - também chamaram a atenção para a importância de se pensar os sentidos como recursos presentes no corpo, e aos quais indivíduos recorrem no trabalho incessante de significar suas existências, para além da dimensão biológica. Em seu livro À la recherche des plaisirs, Tiger, por exemplo, sinaliza que

os seres humanos são seres pensantes, estudiosos e possuem a capacidade de refletir. Contudo, eles também nadam em um mar de sensibilidade, sensualidade, observações internas e externas, julgamentos formados pela visão, olfato, tato, vibração, audição, sede, a noção de passar o tempo, temperatura e movimento, em uma rica variedade de fontes de informação que são utilizadas como guias para a ação. (2003: 283-4) 
Dessa maneira, o conjunto de narrativas faz eco às reflexões de Le Breton (2016: 206) e sua antropologia dos sentidos, uma vez que o sentido tátil funciona, segundo o autor, como veículo primordial para o sujeito moderno em busca de sentido existencial: "a pele faz o sujeito". Para Le Breton, a pele, além de delimitar as dimensões do indivíduo, traz em sua estrutura registros não só físicos, mas inconscientes. A pele "representa o ponto de partida, saturado de inconsciente e cultura", que desvela a articulação entre o psiquismo e a constituição dos vínculos sociais, além de representar o locus de intercâmbio com o mundo, o sentido da proximidade e individualidade, uma espécie de "fronteira" (LE BRETON, 2016: 207) e, ainda, uma "superfície de projeção" (LE BRETON, 2016: 273) que comporta não apenas identificação pessoal, mas ritmos sociais.

Pensando sobre as contribuições de Le Breton e de autores como Dunker, Duarte e Tiger no decorrer do trabalho de campo, é possível refletir que o contato direto da pele de "um" com a pele do "outro" na visão antropológica (a ideia de fronteira) pode dialogar, em certo grau, com a perspectiva psicanalítica que propõe não somente a pele como uma lembrança da exterioridade das coisas, mas como um "litoral". Inicialmente, a ideia de fronteira remete à noção de um ponto fixo, ou rígido - de controle de passagem bem definido - como nas fronteiras entre países, por exemplo. Entretanto, Le Breton aponta que a concepção de fronteira proposta na sua visão antropológica toma a ideia de um ponto que é incessantemente deslocado, promovendo no sujeito o sentimento de sua própria existência, concomitantemente em face do mundo e em alguns momentos misturando-se a ele (LE BRETON, 2016: 257-88).

Observando M. cuidadosamente se depilar, lembro de sua resposta quando perguntei por que a pele "lisinha" era melhor:

Ahhh vai, você é todo peludo, nunca se raspou? (...) quando é lisinho, é como se eu me impregnasse do cara, o pelo atrapalha, é uma barreira, é como se eu lisinho em algum momento eu me misturasse mais nele, e ele se misturasse mais em mim (...) é na pele que a gente sente, né?

Termos presentes nas narrativas como "se misturar" e "se impregnar", entre outras expressões usuais como "tomar" ou "beber o leite" (ingestão do esperma) na prática do "brincar de capa" - quando alguns homens oferecem a outros homens o preservativo contendo sêmen de um ou mais homens -, além do termo "leitar dentro" - termo específico em referência ao ato de ejacular diretamente dentro do ânus do parceiro - denotam que a pele, além de ser considerada uma fronteira entre o eu e o outro, é considerada uma "zona de transgressão" borrada, meio pelo qual o isolamento do sujeito é rompido quando assim deseja.

Tal entendimento aproxima-se à ideia de Georges Bataille (1987: 88-101) de que a "atividade sexual é um momento de crise de isolamento". Buscando ultrapassar criticamente a ênfase do autor em exemplos que tomam por base o que ele mesmo chama "realidade objetiva", a partir das reflexões de Bataille sobre o que formaria, em certo grau, os sujeitos, penso que também seja possível relacionar o desejo de "misturar-se", presente nas narrativas, ao que o autor indica como a consciência dos sujeitos sobre "o caráter descontínuo em relação à vida". As falas evidenciam uma constante consciência de um corpo fadado ao fim, em constantes quadros de crises existenciais, ideia que se aproxima do que Le Breton postula ser uma "distância" (2016: 261) ou separação do outro e Bataille (1987: 12-3) indica ser o "abismo profundo" entre os indivíduos.

Nesse sentido, as palavras de Le Breton (2016: 262) indicam que 
é uma tentativa de conjurar provisoriamente a separação pela apreensão do outro na mesma fruição.

Tal passagem faz relação direta com o que especificamente diz Bataille (1987: 92-96) sobre o erotismo e a noção de descontinuidade inerente ao indivíduo:

(...) da descontinuidade dos seres sexuados procede um mundo pesado, opaco, onde a separação individual tem por base a escuridão; a angústia da morte e da dor deram à parede dessa separação a solidez, a tristeza, a hostilidade de uma parede de prisão. (...) Particularmente na sexualidade, o sentimento dos outros, para além do sentimento de si, introduz entre dois ou mais seres uma continuidade possível, opondo-se à descontinuidade inicial. Os outros na sexualidade não deixam de oferecer uma possibilidade de continuidade, não param de ameaçar, de propor a colocação de um grampo nas vestes sem costura da descontinuidade individual. (...) Cada ser contribui para a negação que o outro faz de si mesmo, mas essa negação não chega de forma alguma ao reconhecimento do parceiro.

Nessa ótica, Dunker (2011: 101) auxilia o esforço de compreender a pele quando aponta que a "carne", uma espécie de "separação entre o real, o simbólico e o imaginário", designa na verdade não uma fronteira bem marcada, mas uma "zona de passagem (...) do visível ao invisível, o ponto de reversão ou de torção da própria visibilidade, e por extensão, de toda a sensibilidade”, que se contrapõe ao corpo biológico à medida que não é apenas dimensional, mas produtora de (inter) subjetividades ${ }^{10}$.

Assim, os termos "tomar uma leitada", "impregnar" e "misturar" presentes nas falas indicam ressignificações quanto ao uso da pele através de práticas que priorizam a "incorporação" de partes de outros sujeitos. Braço, pênis, língua, dedo, consolos, tudo pode ser captado, englobado, absorvido momentaneamente pela "pele" de modo a apaziguar desejos.

\begin{abstract}
Extrato do diário de campo
Diz M em uma conversa informal: "Lembro de uma vez, muitos anos atrás, mais de 10 anos atrás, uma manhã levantei com uma dor no peito enorme, uma agonia, eu estava querendo foder sem camisinha, mas com aquela neura na cabeça... 'sem camisinha?, poxa sem camisinha, sem camisinha'; naquela mesma tarde, esse lugar que a gente conhece como RS, ali na Cinelândia, era ali do lado do Teatro Municipal, num subsolo. Cheguei meio atordoado, não sabia se ia trepar com ou sem camisinha, $e$ teve uma hora que falei pra mim olhando num espelho: 'foda-se!'; vai ser sem, e passei uma tarde e parte da noite ali, trepando sem camisinha com mais de 30 homens, nem lembro quantos, quem chegasse ali querendo me comer, eu dava, era o que eu queria. Terminei aquela loucura machucado, eu sangrava muito, estava todo sujo, os caras ao redor nem aí, mas senti uma calma muito grande também, uma paz inexplicável. Foi estranho, porque aquela dor no peito eu nunca mais tive. Acho que foi ali, naquele dia, que contraí HIV. Um tempo depois, descobri que era positivo, mas foi muito estranho, porque eu senti uma calma enorme também, um alívio mesmo. Eu estava livre da neura, daquela dor no peito que era todo dia, eu agora podia transar pra valer sem me preocupar se ia pegar isso ou aquilo. Quando eu aceitei que essa minha vontade é quem eu sou, que não consigo escapar dela só por querer apenas, eu passei a viver mais feliz comigo, tomo meus remédios, me cuido e tá tudo ótimo”.
\end{abstract}

Inicialmente chamo a atenção para o paradoxo que identifico na fala de M. e de tantos outros homens com quem convivi: a mesma pele que engloba e acolhe partes do outro, se dilacera, sangra e provoca alívio no sujeito. Sobre este aspecto, encontro nas reflexões de Ferraz (2014: 62) algumas orientações para pensar a pele. A autora aponta para uma perspectiva que concebe a pele como um "estatuto paradoxal".

${ }^{10}$ Adicionalmente, convoco Mary Douglas (2012: 14) para o debate para pensar que "algumas vezes, orifícios corporais parecem representar pontos de entrada e saída para unidades sociais, ou a perfeição corporal pode simbolizar uma teocracia ideal”, isto é, a pele no contexto do sexo "sem capa" alinha-se à noção de fronteira mais uma vez. 
Influenciada pelos estudos do pesquisador português José Gil e numa curiosa discussão sobre corporeidade e sentido de continuidade entre os sujeitos no mundo contemporâneo, a autora introduz um exemplo curioso: o advento do material inorgânico teflon, nome comercial de um polímero acidentalmente descoberto em 1930 e registrado pela empresa americana DuPont, em 1946. Ferraz, ao relembrar as dificuldades para se fritar um ovo antes do teflon, aponta para o "embate épico" entre a resistência e viscosidade próprias ao orgânico e as propriedades inorgânicas sem atrito do teflon e realiza uma analogia a modos de vida na contemporaneidade que priorizam a hegemonia de corpos que chama de "carapaça" ou "fortaleza vazia" (2014: 66), "fechados em si - ou, como denomina, "corpos zumbi”.

Nessa visão, nos encontros em que estive presente, foi possível observar homens praticantes de sexo bareback que priorizam, antes de mais nada, o inverso da caracterização do corpo "carapaça” proposto por Ferraz, isto é, priorizam a pele e o "roça-roça", a porosidade da pele como porta de entrada e comunicação com o mundo exterior, de modo a transformarem seus cotidianos em experiências prazerosas. Sobre a pele, diz a autora que

\begin{abstract}
lembremos também que, se podemos ser tocados de modo indolor, tal se dá exatamente porque nossa pele possui essa textura paradoxal: a de uma superfície dotada de certa profundidade. Por isso também ela é sempre renovada, ao mesmo tempo viva "em profundidade" e "superficialmente" morta, nela se embaralhando a oposição nítida entre vida e morte. Como se sabe, a descamação ininterrupta e cotidiana de nossas peles, em certas condições climáticas tropicais, fornece alimento para gulosos pequenos seres como os ácaros, que vivem (e se reproduzem) em nossas camas enquanto dormimos em paz.
\end{abstract}

Retomando a discussão proposta por Alberti e Bataille sobre a descontinuidade radical constitutiva dos sujeitos e do que Lacan chama de "litoral", relembro o trecho da conversa com M.:

Terminei aquela loucura machucado, eu sangrava muito, estava todo sujo, minha pele marcada, os caras ao redor nem aí, um pouco de cada um deles dentro de mim, assustador, mas senti uma calma muito grande também, uma paz inexplicável.

Ao pensar que a ausência do limite físico entre a pele e o objeto de desejo, mais especificamente a ausência de barreiras entre M. e seus objetos de desejo, é parte da constituição de quem ele é, é possível inferir que a busca pelo outro e a mistura é capaz de prover uma sensação de completude (ainda que fugaz), continuidade momentânea apaziguadora das tensões do cotidiano. Logo, pensando nas palavras de M., e nas diversas conversas com outros homens em mesas de bares antes e depois das reuniões das quais participei, é possível registrar que escutava aqui e ali frases como: "É bom demais, aquela sensação de alívio boa, nem dá pra explicar direito depois de uma foda pra valer"; "É hora de extravasar!" - o prazer experimentado a partir da transgressão de uma norma, da testagem de seus próprios limites.

A angústia da descontinuidade - inerente ao sujeito - afeto do qual não pode escapar ${ }^{11}$ parece se tornar menor (ainda que momentaneamente) diante da possibilidade da experiência de continuidade na fusão com o outro. A "calma" que M. e muitos homens relatam após suas experiências, me leva a pensar que o sexo "na pele" apazigua, em certo grau, uma angústia cotidiana resultante de diferentes contextos nos quais estes homens estão inseridos. É na ação do atrito, na troca

${ }^{11}$ Sobre o afeto de angústia como algo inerente ao sujeito, ver mais em "Alice ou a última fuga: o afeto de angústia em cena" (BEZERRA, 2018). 
direta dos fluidos, na transgressão à norma estabelecida que reprime - que a angústia parece se tornar menor. É na possibilidade da experiência, ainda que fugaz, da continuidade através da fusão "violenta" com o outro, que estes homens, em algum grau, encontram prazer.

Para Bataille, é justamente a violência (e aqui pode-se entendê-la como a "desordem" ou a aniquilação momentânea da angústia realizada pelos sujeitos) que poderia assim fazer vir à tona essa passagem de uma atitude interdita, tensa, restrita, fechada à assunção dos sujeitos da "fissura", que se abrem a este elemento considerado pelo autor como a "mola do prazer" (1987: 98); atos aparentemente violentos (práticas sexuais extremas, abuso verbal, físico), tudo impulsiona o caminho em direção ao prazer que buscam.

Da mesma forma, também podem ser consideradas as formulações de Le Breton (2016) sobre a pele em sua antropologia dos sentidos, que indica, na contemporaneidade, a criação de "atalhos" pelos indivíduos na tentativa de apaziguarem e reorganizarem um caos interior particular (a tensão?), imprimindo sentido à sua própria existência ao obter a sensação de plenitude, ou completude provisoriamente alcançada. Nas palavras de Le Breton (2016: 207), a pele

\footnotetext{
é principalmente um limite de sentido e de desejo, religa e separa, organiza a relação com o mundo, é instância de regulação, um filtro ao mesmo tempo físico e somático. (...) é saturada de inconsciente e de cultura, ela desvela o psiquismo do sujeito, mas também a parte que ele assume no interior do vínculo social (...). O público e o privado juntam-se nela. A pele é o ponto de contato com o mundo, e com os outros. Ela sempre é uma matéria de sentido.
}

O conjunto de experiências observadas também faz eco às reflexões do pesquisador Luiz Fernando Dias Duarte (1999: 21-30), no artigo "O império dos sentidos: sensibilidade, sensualidade e sexualidade na cultura ocidental moderna", que ajudam a pensar a questão do sexo bareback no contexto da cultura ocidental, partindo da ideia que situa o sentido e o papel da sexualidade "num universo maior de significação" (DUARTE, 1999: 23; DUARTE et al.; 2018). O autor articula a própria ideia de sexualidade com os conceitos de sensualidade e sensibilidade e afirma que o termo, além de ter passado por processos de transformação ao longo do tempo, encontra-se em "uma série de desenvolvimentos do que Michel Foucault (1977) chamou de 'dispositivo da sexualidade" (DUARTE, 1999: 23). Neste ponto, Duarte chama a atenção para a valorização dos sentidos, que pode ser entendida como uma tendência dos sujeitos na busca da perfectibilidade - capacidade própria dos sujeitos ao aperfeiçoamento a partir do uso da razão, da preeminência da experiência - por meio dos sentidos e do fisicalismo - na busca de um prazer que ultrapassa o genital e se expande através da exploração da mente e do corpo.

Trazendo como referências os trabalhos de autores clássicos como Norbert Elias (1990) e Louis Dumont (1985), o autor observa que, entre os séculos XVII e XVIII, há a constituição, no Ocidente, do que chama de um "dispositivo de sensibilidade" (DUARTE, 1999: 24), que surge no mesmo momento histórico em que Foucault localiza o surgimento do dispositivo da sexualidade, a passagem da lógica do sangue para a da sexualidade, do dispositivo de aliança para o da sexualidade. Dessa maneira, é possível pensar que a valorização efetuada pelos homens praticantes de sexo bareback ao termo "foda pra valer", dentro dos grupos observados, pode indicar que o universo das experiências de sexo sem preservativo pode ser entendido como um fenômeno inscrito nas dimensões não apenas da sexualidade, mas da sensualidade (já introduzida por Tiger) e, mais detidamente, da sensibilidade, no sentido proposto por Duarte. 
A pele que se rompe, o sangue que escorre, a saliva, o suor e o sêmen trocados dinamicamente - fluidos oferecidos como dádivas - compõem a dimensão do sexo "na pele" e parecem apontar para o que Duarte (1999: 24-5) indica como a tendência dos sujeitos à "preeminência da experiência":

\begin{abstract}
(...) a razão humana só viceja através do contato dos sujeitos com o mundo propiciado pelos "sentidos"; ela depende da maneira pela qual eles percebem o mundo que os cerca, e é através desses sentidos que vão poder construir as suas novas formas de relação com o mundo e se tornar eventualmente cada vez mais aperfeiçoados, mais capazes, mais senhores de seu futuro.
\end{abstract}

Nessa perspectiva, os sentidos, em especial o olfativo e o tátil, assumem hegemonia e subvertem, em parte, a clássica ideia de que os fluxos corporais estariam ligados ao perigo e à "poluição" dos corpos. E por que em parte?

Em Pureza e perigo, Mary Douglas (2012: 14) indica que "ao examinarmos crenças de poluição descobrimos que os tipos de contato tidos como perigosos também carregam uma carga simbólica”. Isto é, algumas "poluições", segundo a autora, são utilizadas como analogias para expressar uma visão geral da ordem social. Contudo, ainda que clássicas delimitações entre os papéis e hierarquias nessas interações estivessem presentes (ativo/passivo, bofe/bicha, preto/ branco) ${ }^{12}$, o que parece imprescindível apontar aqui é que o cheiro de fezes no ambiente, a urina sobre os corpos, o forte odor de suor, o sangue na pele dilacerada e o sêmen ingerido - imagens sistematicamente vistas por mim (e que muitas vezes) causaram incômodo - funcionavam para estes homens como um "modelo de colaboração" e "absorção política" (DOUGLAS, 2012: 14). Isto é, a transgressão da norma do "sexo higiênico" ou a negação da ordem serviam não somente como mola propulsora de seus prazeres, mas de ferramenta para um enfrentamento político frente ao contexto social repressor do cotidiano. Sobre isso, diz Douglas (2012: 14) que, "algumas vezes, orifícios corporais parecem representar pontos de entrada e saída para unidades sociais". "Eu sou o dono do meu cu, Vladimir! É um tal de camisinha aqui, proteção dali."

Sob esta ótica, os dados da pesquisa informam que os sentidos se encontram tanto na raiz da razão como na da "imaginação" ou das "emoções" e "paixões" desses homens. Tal entendimento apoia-se nas pontuações de Duarte (1999: 259), que indica que a relação entre o dispositivo de sensibilidade e o dispositivo da sexualidade apresenta-se como um fenômeno complexo, uma vez que " o fato cognitivo da 'experiência' se reduplica em fato emocional". Logo, pensar a sexualidade destes homens implica pensar que a pele ultrapassa, em diversos momentos, suas propriedades biológicas para articular-se com as dimensões moral, estética e psicológica das emoções sensíveis. O próprio Duarte brilhantemente coloca a questão: por que usar preservativo, se este recurso técnico pode ser considerado frequentemente como algo que limita o prazer?

Ao introduzir o questionamento sobre o uso do preservativo, Duarte (1999: 28) aponta que na contemporaneidade existe uma tensão entre os sujeitos no sentido de suas vivências: "trata-se da tensão entre a maximização da vida (através da totalidade da pessoa), que é um investimento no longo prazo e na duração, e a otimização do corpo (através da concentração de prazer), que é uma aposta no curto prazo e na intensidade".

Tensão que a experiência do trabalho de campo revelou cotidianamente: "Vladimir, porque diminuir meu prazer e ficar de pau mole a vida toda, se posso gozar de pau duro e ser mais feliz hoje? Viver é fazer contato, cara!"

${ }^{12}$ Ver mais sobre a construção da identidade homossexual no Brasil em Fry (1982). 


\section{Considerações finais}

A pele - dentro da experiência "sem capa" - parece viabilizar processos complexos de sexualidade, sensualidade e sensorialidade e se inscreve numa dimensão multidimensional, isto é, física, política e simbólica, que contribui para processos de identificação entre seus praticantes. A preponderância, nas falas, do termo "pra valer" e sua ligação direta com os termos "no pelo", "pele" e "na pele" apontam para o fato de que o sexo bareback não permite "intermediários" (no caso, a borracha), uma vez que entre seus praticantes o sentido tátil funciona como veículo primordial em busca de sentido existencial, assim como na passagem "a pele faz o sujeito" (LE BRETON, 2016: 206).

De modo geral, as narrativas indicam que a pele, além de delimitar o lugar do indivíduo no mundo, traz em sua estrutura registros não apenas físicos oriundos da exterioridade (marcas, por exemplo), mas inconscientes (reminiscências) de suas vidas vividas, fato muito presente no trabalho clínico. As diversas ocasiões em que presenciei não apenas a preparação da pele (sua raspagem, ornamentação e hidratação), mas as potencialidades de seu uso durante o sexo sem preservativo (sua elasticidade, por exemplo), indicam que a pele é pensada pelos sujeitos como "o ponto de partida" ou "superfície de projeção" não apenas de processos subjetivos, mas de sua relação com a cultura - a pornografia bareback, por exemplo.

Nessa relação entre o psiquismo e a constituição dos vínculos sociais, a pele parece representar a zona de intercâmbio com o mundo, não somente no sentido da proximidade com o outro (e completude fugaz), mas o locus da individualidade, num processo paradoxal dinâmico que articula identificação pessoal (ou um processo psíquico particular) e ritmos sociais. A porosidade, a elasticidade e as terminações nervosas da pele funcionam não como um fim apenas, mas representam uma via criada, aperfeiçoada, testada para a obtenção do prazer e realização dos desejos, o que faz com que esses sujeitos priorizem o contato direto, sem a intermediação da "borracha", anunciando a importância do que Duarte indica ser o "dispositivo da sensibilidade".

Dada a amplitude das questões mencionadas, fica aqui registrado o desejo de que essas pequenas reflexões, que jamais poderiam esgotar a discussão, sirvam para animar a interlocução com diferentes pesquisadores do campo do gênero e da sexualidade, provocando outros questionamentos que resultem não somente em mais estudos, mas no desenvolvimento de práticas clínicas que busquem menos explicações e muito mais compreensões sobre as metamorfoses entre o social e o sexual nos sujeitos. 


\section{Referências}

ALBERTI, Sonia. "Psicanálise e corpo em pesquisa”. In: RAMIREZ, H. H. A.; ASSADI, Tatiana Carvalho; DUNKER, Christian Ingo Lenz (orgs.). A pele como litoral: fenômeno psicossomático e psicanálise. São Paulo: Annablume, 2011.

AZERÊDO, Sandra. Gênero e a diferença que ele faz na pesquisa em psicologia. Cadernos Pagu, 11: 55-66, 1998.

. Encrenca de gênero nas teorizações em psicologia. Estudos Feministas, 18 (1): 175-188, 2010.

BATAILLE, Georges. O Erotismo. Porto Alegre: L\&PM, 1987.

BEZERRA, Vladimir. Alice ou a última fuga: o afeto de angústia em cena. Entheoria: Cadernos de Letras e Humanas, 5 (1): 12-21, 2018.

BEZERRA, Vladimir. O sexo "na pele": sentidos do corpo e da pele na experiência bareback entre homens na cidade do Rio de Janeiro. Dissertação de Mestrado, Ciências Sociais, Pontifícia Universidade Católica do Rio de Janeiro, 2019.

BEZERRA, Vladimir; GIACOMINI, Sonia. “O sexo "sem capa”: notas etnográficas sobre o corpo na experiência bareback entre homens". In: VILHENA NOVAES, Joana de; VILHENA, Junia de (orgs.). O que pode um corpo? Diálogos interdisciplinares. Curitiba: Appris, 2019.

BEZERRA, Vladimir; SILVA, Vera Lúcia Marques da. "Bareback, Risco e Prazer na Perspectiva de Usuários da Profilaxia Pré-exposição (PrEP) ao HIV: um estudo netnográfico". In: OLIVEIRA, Thiago; MAIA, Helder Thiago (orgs.). Práticas sexuais: itinerários, possibilidades \& limites de pesquisa. Salvador: Devires, 2019.

BIRMAN, Joel. Mal-estar na atualidade. A psicanálise e as novas formas de subjetivação. Rio de Janeiro: Civilização Brasileira, 1999.

BIRMAN, Joel. A physis da saúde coletiva. Physis, 1 (1): 7-11, 1991.

BIRMAN, Joel. As pulsões e seus destinos: do corporal ao psíquico. Rio de Janeiro: Civilização Brasileira, 2009.

BORGES, S. N. Metamorfoses do corpo: uma pedagogia freudiana. Rio de Janeiro: Fiocruz, 1996.

BRASIL. Ministério da Saúde. Pesquisa de conhecimento, atitudes e práticas na população brasileira. Secretaria de Vigilância em Saúde. Departamento de DST, AIDS e Hepatites Virais. Série G. Estatística e Informação em Saúde. Brasília: Ministério da Saúde, 2011.

BRASIL. Ministério da Saúde. Boletim epidemiológico HIV/AIDS. Secretaria de Vigilância em Saúde - Departamento de Vigilância, Prevenção e Controle das Infecções Sexualmente Transmissíveis, do HIV/Aids e das Hepatites Virais. Ano V, n.1 $-27^{\mathrm{a}}$ a $53^{\mathrm{a}}$ - semanas epidemiológicas - julho a dezembro de 2016; ano V - n.1 - $1^{\mathrm{a}}$ a $26^{\mathrm{a}}$ - semanas epidemiológicas - janeiro a junho de 2017. Brasília: Ministério da Saúde, 2017a.

BRASIL. Ministério da Saúde. Boletim epidemiológico Sífilis. Secretaria de Vigilância em Saúde - Departamento de Vigilância, Prevenção e Controle das Infecções Sexualmente Transmissíveis, do HIV/Aids e das Hepatites Virais. V. 48, n. 36. Brasília: Ministério da Saúde, 2017b. 
BRAZ, Camilo. À meia luz: uma etnografia em clubes de sexo masculinos. Goiania: UFG, 2012.

BUTLER. Judith. Gender trouble. New York: Routledge, 2006.

CANGUILHEM, Georges. O normal e o patológico. Rio de Janeiro: Forense, 2009.

CARRARA, Sérgio; SIMOES, Júlio Assis. Sexualidade, cultura e política: a trajetória da identidade homossexual masculina na antropologia brasileira. Cadernos Pagu, 28: 65-99, 2007.

CASTIEL, Luis David; GUILAM, Maria Cristina Rodrigues.; FERREIRA, Marcos Santos. Correndo o risco: uma introdução aos riscos em saúde. Rio de Janeiro: Fiocruz, 2010.

DAMATTA, Roberto. Relativizando: uma introdução à Antropologia Social. Rio de Janeiro: Rocco, 2010.

DAMATTA, Roberto. "O ofício do etnólogo, ou como ter o anthropological blues". In: NUNES, E. (org.). A Aventura sociológica. Rio de Janeiro: Zahar, 1978. pp. 23-35.

DEBORD, Guy. A sociedade do espetáculo. Rio de Janeiro: Contraponto, 1997.

DÍAZ-BENÍTEZ, María Elvira. Dark Room aqui: um ritual de escuridão e silêncio. Cadernos de Campo, 16 (16): 93-112, 2007.

DOUGLAS, Mary; WILDAVSKY, Aaron. Risco e Cultura: um ensaio sobre a seleção de riscos tecnológicos e ambientais. Rio de Janeiro: Elsevier, 2012.

DOUGLAS, Mary. Pureza e perigo. São Paulo: Perspectiva, 2012.

DOURADO, Inês. et al. Revisitando o uso do preservativo no Brasil. Revista Brasileira de Epidemiologia, 18 (supl.1): 63-88, 2015.

DUARTE, Luiz Fernando Dias. "O império dos sentidos: sensibilidade, sensualidade e sexualidade na cultura ocidental moderna”. In: HEILBORN, Maria Luíza (org.). Sexualidade: o olhar das ciências sociais. Rio de Janeiro: Zahar, 1999. pp. 21-30.

DUARTE, Luiz Fernando Dias. Antropología y psicoanálisis: retos de las ciências románticas en el siglo XXI. Culturas Psi, 1 (1): 45-63, 2013.

DUMONT, Louis. O Individualismo: Uma perspectiva antropológica da ideologia moderna. São Paulo: Rocco, 1985.

DUNKER, Christian Ingo Lenz. "Corporeidade em Psicanálise: corpo, carne e organismo". In: RAMIREZ, Heloísa Helena Aragão; ASSADI, Tatiana Carvalho; DUNKER, Christian Ingo Lenz (orgs.). A pele como litoral: fenômeno psicossomático e psicanálise. São Paulo: Annablume, 2011.

ELIAS, Norbert. O Processo Civilizador: vol. 1 - Uma História dos Costumes, Rio de Janeiro: Jorge Zahar Editor, 1990.

FERRAZ, Maria Cristina Franco. Estatuto paradoxal da pele e cultura contemporânea: da porosidade à pele-teflon. Galaxia, 14 (27): 61-71, 2014.

FORTES, Isabel; WINOGRAD, Monah; PERELSON, Simone. Algumas reflexões sobre o corpo no cenário psicanalítico atual. Psicologia USP, 29 (2): 277-284, 2018. 
FOUCAULT, Michel. A história da sexualidade I: a vontade de saber. Rio de Janeiro: Graal, 1977.

FREUD, Sigmund. A interpretação dos sonhos. Porto Alegre: L\&PM, 2012.

FREUD, Sigmund. Edição Standard Brasileira das Obras Psicológicas Completas de Sigmund Freud. Rio de Janeiro: Imago, 1974.

FRY, Peter. Para inglês ver: identidade e política na cultura brasileira. Rio de Janeiro: Zahar.

GEERTZ, Clifford. A interpretação das culturas. Rio de Janeiro: Zahar, 2004.

LACAN, Jacques. Escritos. Rio de Janeiro: Zahar, 1998.

LASCH, Christopher. A cultura do narcisismo. Rio de Janeiro: Imago, 1983.

LE BRETON, David. Antropologia dos sentidos. Petrópolis: Vozes, 2016.

LE BRETON, David. Passions du risque. Paris : Metaillé, 2000.

LE BRETON, David. Conduites à risque: des jeux de mort au jeu de vivre. Paris: Quadrige, 2013.

LE BRETON, David. Antropologia do corpo e modernidade. Petrópolis: Vozes, 2011.

LE BRETON, David. Aqueles que vão para o mar - o risco e o mar. Revista Brasileira de Ciências do Esporte, 28 (3): 9-19, 2007.

LOYOLA, Maria Andrea (org.). AIDS e sexualidade: o ponto de vista das ciências humanas. Rio de Janeiro: Relume-Dumará/UERJ, 1994.

MALINOWSKI. Bronislaw. Argonautas do pacífico ocidental: um relato do empreendimento e da aventura dos nativos nos arquipélagos da Nova Guiné - Melanésia. São Paulo: Abril, 1978.

MAKSUD, Ivia.; FERNANDES, Nilo Martinez; FILGUEIRAS, Sandra Lúcia. Tecnologias de Prevenção do HIV e desafios para os serviços de saúde. Rev. brasileira de epidemiologia, 18 (supl. 1): 104-19, 2015.

MELLO, Anahi Guedes de. Deficiência, incapacidade e vulnerabilidade: do capacitismo ou a preeminência capacitista e biomédica do Comitê de Ética em Pesquisa da UFSC. Ciência \& Saúde Coletiva, 21 (10): 3265-3276, 2016.

MIJOLLA, Alain de. Dicionário internacional de Psicanálise. Rio de Janeiro: Imago, 2005.

PARKER, Richard; BARBOSA, Regina Maria. Sexualidades brasileiras. Rio de Janeiro: Relumé-Dumará, 1996.

RAMIREZ, Heloísa Helena Aragão; ASSADI, Tatiana Carvalho; DUNKER, Christian Ingo Lenz (orgs.). A pele como litoral: fenômeno psicossomático e psicanálise. São Paulo: Annablume, 2011.

ROCHA, Evaristo; FRID, Marina. Os antropólogos: clássicos das Ciências Sociais. Petrópolis: Vozes; Rio de Janeiro: PUC, 2015.

RUSSO, Jane. "A construção social do corpo: desnaturalização de um pressuposto médico". In: PITANGUY, Jaqueline (org.). Saber médico, corpo e sociedade. Rio de Janeiro: CEPIA, 1998. pp. 51-60. 
RUSSO, Jane. "Uma leitura antropológica do mundo psi”. In: VILELA, Ana Maria Jacó; JABUR, Fabio; RODRIGUES, Heliana Conde (orgs.). Clio-psyché: Histórias da psicologia no Brasil. Rio de Janeiro: UERJ, 1999. pp. 67-74.

SILVA, Hélio. A situação etnográfica: andar e ver. Horizontes antropológicos, 15 (32): 171-88, 2009.

SILVA, Cristina Dias. A ética em debate: o trabalho de campo e seus novos desafios. Anuário antropológico (2004), 30 (1): 187-198, 2005.

SILVA, Luis Augusto Vasconcelos. Barebacking e a possibilidade de soroconversão. Cadernos de Saúde Pública, 25 (6): 1381-89, 2009.

SPINK, Mary Jane. Trópicos do discurso sobre risco: risco - aventura como metáfora na modernidade tardia. Cadernos de Saúde Pública, 17 (6): 1277-1311, 2001.

TIGER, Lionel. À la recherche des plaisirs. Paris: Payot, 2003. 